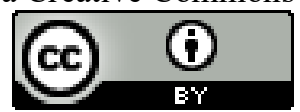

\title{
O SILÊNCIO NA FORMAÇÃO E O REFLEXO NA SALA DE
} AULA: POR ONDE ANDAM AS QUESTÕES RACIAIS NA
CONSTRUÇÃO DO FUTURO PROFESSOR DE CIÊNCIAS E BIOLOGIA?

\author{
Felipe Ramon Santos ${ }^{1}$ \\ Universidade Federal do Ceará, Centro de Ciências, Departamento de Biologia, \\ Fortaleza, CE, Brasil.
}

\begin{abstract}
Resumo: Este trabalho busca analisar o processo de formação de professores do curso de licenciatura em Biologia no que diz respeito às questões raciais. Os questionamentos surgiram a partir das vivências que a formação docente me proporcionou e é através destas narrativas que busco analisar a existência dos eventos de silenciamento para com as questões raciais na formação dos futuros professores desta área. Para a realização dessa pesquisa foi elaborado um questionário virtual destinado a todos os professores que ministram disciplinas ao curso de Ciências Biológicas da Universidade Federal do Ceará. O questionário a principal ferramenta metodológica da pesquisa foi enviado para 76 docentes tendo ao final de 21 dias um total de 14 respondentes. Analisando desde a quantidade de respondentes até as suas respostas é possível perceber uma predisposição a ocorrência desse silenciamento e suas marcas que perpassam a formação, e é refletida diretamente na prática docente na sala de aula
\end{abstract}

Palavras-Chave: Identidade; formação; racismo.

\section{SILENCE IN TRAINING AND REFLECTION IN THE CLASSROOM: WHERE DO RACIAL ISSUES GO IN BUILDING THE FUTURE SCIENCE AND BIOLOGY TEACHER?}

\begin{abstract}
This work seeks to analyze the process of training teachers in the Biology degree course with regard to racial issues. The questions arose from the experiences that teacher training provided me and it is through these narratives that I seek to analyze the existence of silencing events towards racial issues in the training of future teachers in this area. To carry out this research, a virtual questionnaire was designed for all professors who teach courses in Biological Sciences at the Federal University of Ceará. The questionnaire, the main methodological tool of the research, was sent to 76 professors, with a total of 14 respondents at the end of 21 days. Analyzing from the number of
\end{abstract}

\footnotetext{
${ }^{1}$ Licenciado em Ciências Biológicas pela Universidade Federal do Ceará (2020). Professor de Ciências e Biologia. E-mail: framons16@gmail.com; ORCID: https://orcid.org/0000-0001-6023-4325
} 
respondents to their responses, it is possible to see a predisposition to the occurrence of this silencing and its marks that permeate training, and is directly reflected in the teaching practice in the classroom.

Keywords: Identity; Formation; racism.

\section{SILENCIO EN LA FORMACIÓN Y REFLEXIÓN EN EL AULA: ¿A DÓNDE VAN LOS PROBLEMAS RACIALES EN LA FORMACIÓN DEL FUTURO PROFESOR DE CIENCIAS Y BIOLOGÍA?}

Resumen: Este trabajo busca analizar el proceso de formación de los docentes de la carrera de Biología en materia racial. Las preguntas surgieron de las experiencias que me brindó la formación docente y es a través de estas narrativas que busco analizar la existencia de eventos silenciadores hacia la temática racial en la formación de futuros docentes en esta área. Para llevar a cabo esta investigación, se diseñó un cuestionario virtual para todos los profesores que imparten cursos de Ciencias Biológicas en la Universidad Federal de Ceará. El cuestionario, principal herramienta metodológica de la investigación, se envió a 76 profesores, con un total de 14 encuestados al término de 21 días. Analizando desde el número de encuestados hasta sus respuestas, es posible ver una predisposición a la ocurrencia de este silenciamiento y sus marcas que permean la formación, y se refleja directamente en la práctica docente en el aula

Palabras-clave: Identidad; formación; racismo.

\section{SILENCE DANS LA FORMATION ET RÉFLEXION EN CLASSE: OÙ VONT LES QUESTIONS RACIALES DANS LA CONSTRUCTION DU FUTUR PROFESSEUR DE SCIENCES ET DE BIOLOGIE?}

Résumé: Ce travail vise à analyser le processus de formation des enseignants de la licence Biologie au regard des questions raciales. Les questions sont nées des expériences que la formation des enseignants m'a fournies et c'est à travers ces récits que je cherche à analyser l'existence d'événements de silence envers les questions raciales dans la formation des futurs enseignants dans ce domaine. Pour mener à bien cette recherche, un questionnaire virtuel a été conçu pour tous les professeurs qui enseignent des cours en sciences biologiques à l'Université fédérale du Ceará. Le questionnaire, principal outil méthodologique de la recherche, a été envoyé à 76 professeurs, avec un total de 14 répondants au bout de 21 jours. En analysant du nombre de répondants à leurs réponses, il est possible de voir une prédisposition à l'apparition de ce silence et de ses marques qui imprègnent la formation et se reflètent directement dans la pratique pédagogique en classe.

Mots-clés: Identité; Formation; racisme.

(RE)VISITANDO MEUS CAMINHOS: A MINHA HISTÓRIA CONTA A HISTÓRIA DE OUTROS 
Este trabalho busca analisar o processo de formação de professores do curso de licenciatura em Biologia no que diz respeito às questões raciais. O questionamento surge a partir das vivências que a formação docente me proporcionou e através destas narrativas que busco analisar o evento de silenciamento em relação às questões raciais na formação dos futuros professores desta área.

Ao refletir sobre o meu processo de formação como futuro professor de ciências e biologia percebo que, para além das experiências das disciplinas de conteúdo específico do curso de Ciências Biológicas e das reflexões pedagógicas ocorridas no conjunto de disciplinas voltadas para as licenciaturas, que as minhas observações, aflições e questionamentos foram cruciais no meu "tornar-se professor".

O primeiro grande questionamento que fiz foi acerca do "eu" e da minha presença. Onde muitas vezes me senti só e não pertencente ao ambiente em que estava. Só com o passar do tempo entendi os porquês dessa sensação de solidão. Foi quando me organizei dentro de um movimento social de juventude e militei no movimento estudantil da UFC, que comecei a observar de maneira mais crítica e embasada meu lugar por meio do que me rodeava e percebia pela primeira vez o que é ser negro.

Entender-se negro é perceber que existe uma estrutura invisível que segrega até os espaços de formação de conhecimento e que mente sobre uma falsa igualdade que na verdade mantém e perpetua uma antiga e conhecida relação de poder. Notar que o racismo perpassa ações de ataque individual, mas está presente até nas camadas mais internas dos nossos processos formativos. Foi dentro desse mar de contradições que entendi a minha posição, eu, negro, morador periférico, futuro professor estava ocupando um espaço de privilégio. E que entender meu desconforto era crucial para compreender essa estrutura.

Não faz muito tempo que conceitos biológicos e científicos são utilizados para embasar a segregação racial, o que pode ser chamado de racismo científico.

Embora Charles Darwin não tenha se detido muito nas explicações sobre raças humanas em a Origem das Espécies, fez isso em 1871, em a Origem do Homem, obra que evidencia, coerentemente com os pressupostos da seleção natural, a existência de raças humanas e de gradientes evolutivos entre elas, corroborando com a teoria de conhecimento proposta pelo criacionista Linné um século antes. Tais proposições sustentaram o racismo científico e o atestado de autenticidade para a dominação de povos sobre povos dentro de um mesmo Estado e entre Estados diferentes, representados por suas populações raciais. Nesse sentido, instauram-se no cenário mundial políticas norteadas pela dominação racial. (VIEIRA, 2015, p. 25) 
Os professores de ciências e biologia dentro de suas salas abarrotadas de alunos, todos os dias tratam de diversos conteúdos de teor científico, como a célula, meio ambiente, reações químicas, enfim, um conjunto amplo de conteúdos obrigatórios, designados pelos documentos oficiais, que traçam o perfil das aulas dessas disciplinas na escola. A importância desses conteúdos na formação dos estudantes é inegável, afinal, são temas que transpassam as ciências da natureza e dão base a diversas áreas importantíssimas na nossa sociedade.

Entretanto, as disciplinas de estágio no ensino fundamental e médio que são atividades curriculares inseridas no curso de formação como docente em Biologia, me proporcionaram confirmar o que já me afligia. Se dentro das salas de aula na universidade, no curso de licenciatura, as discussões sobre o racismo não existiam, a realidade na escola não seria muito diferente. Então encontrei uma imagem esterilizada e "neutra" da Ciência que fragmenta os conteúdos e dilui a discussão racial tornando-a irrelevante para ser debatida no horário que se é reservado para as disciplinas de ciências e biologia na escola.

Perceber essa realidade me fez retornar imediatamente à minha época de ensino fundamental com uma profunda dor e reflexão. Só depois de adulto é que consegui dar nome ao racismo que sofria naquela época e agora, como futuro professor, me pesa nos ombros a responsabilidade de mudar essa realidade, pelo menos onde estiver.

Com isso, questiona-se: "por onde andam as discussões raciais na formação do professor de ciências e biologia?". O questionamento é relevante quando se leva em consideração o meu papel como futuro professor dessas disciplinas e na urgência da superação do racismo em nossa sociedade e, para isso, o debate de raça é central também quando falamos sobre educação. De acordo com Almeida (2018, p. 37), “em uma sociedade em que o racismo está presente na vida cotidiana, as instituições que não tratarem de maneira ativa e como um problema a desigualdade racial irão facilmente reproduzir as práticas racistas já tidas como "normais" em toda sociedade". Com isso percebe-se que as instituições de ensino em todos os seus níveis, do básico ao superior, não estão isentas na perpetuação do racismo em qualquer uma de suas faces.

Nós, futuros professores e pesquisadores, necessitamos que na nossa formação essas discussões estejam presentes e asseguradas a partir das bases curriculares que nos norteiam.

Um currículo crítico que se preocupasse com a questão do racismo poderia precisamente colocar no centro de suas estratégias pedagógicas a noção de 
representatividade tal como defendida pelos Estudos Culturais. Essa noção permitiria deslocar a ênfase de uma preocupação realista com a verdade para uma preocupação política com as formas pelas quais a identidade é construída através da representação (SILVA, 2015, p.103).

Compreender as aulas de ciências e de biologia como um local de discussões sociais, quebra os preceitos de falsa neutralidade científica e cria um ambiente crítico onde o aprender ciências e biologia foge do entender processos, transformando-se na percepção da complexibilidade dos organismos e ambientes.

Essas percepções me levaram a investigar, a partir da minha ocupação como estudante de um curso de uma universidade pública, elementos que pudessem auxiliar a compreensão dessas inquietações. Através dessas reflexões sobre os momentos de desconforto na sala de aula do estágio, associando-as também ao meu percurso nas demais vivências na universidade, que pude questionar-me sobre a existência de um evento de silenciamento das questões e formulações étnico-raciais na formação do professor de ciências e biologia.

Esse questionamento foi inicialmente materializado na forma da minha pesquisa de Trabalho de Conclusão de Curso (TCC) em Licenciatura em Ciências Biológicas e agora reorganizado como artigo científico. Possuindo como objetivos analisar o evento de silenciamento das questões étnico-raciais na formação dos futuros professores de ciências e biologia na universidade pública. Além de tentar compreender os motivos que geram o silenciamento das questões étnico-raciais na formação dos docentes em ciências e biologia através da discussão da importância dos temas antirracistas na licenciatura em Ciências Biológicas a partir do olhar dos docentes.

\section{OS SUPORTES TEÓRICOS}

A importância de discussões de cunho racial em locais onde esses assuntos são silenciados, como a escola, é crucial para a superação do racismo estrutural que perpassa a nossa sociedade, e com isso, me baseio em conceitos importantes acerca do racismo estrutural como lente que norteia à análise e interpretação de nosso contexto social. Almeida (2018) salienta:

Consciente de que o racismo é parte da estrutura social e, por isso, não necessita de intenção para manifestar, por mais que calar-se diante do racismo não faça do indivíduo moral e/ou juridicamente culpado ou responsável, certamente o silêncio 
o torna ética e politicamente responsável pela manutenção do racismo. A mudança da sociedade não se faz apenas com denúncias vazias ou repúdio moral do racismo: depende, antes de tudo, da tomada de postura e adoção de práticas antirracistas (ALMEIDA, 2018, p. 40).

Para tanto, é preciso entender a Ciência (aqui entendida como produtora de conhecimento) e o seu ensino como locais que necessitam urgentemente debater as questões raciais, pois historicamente, a Ciência foi "isenta" desses debates.

Na modernidade, a forma hegemônica da ciência e da tecnologia está impregnada dos aromas de uma suposta neutralidade, no qual seu cheiro indica que a ciência está isenta dos demais acontecimentos da vida social. Tal perspectiva influenciou o ensino da área de Ciências da Natureza e teve suas fontes de origem nos escritos de Bacon, no século XVI. Em sua obra Novum Organum, ele dizia ter a ciência somente bondade e neutralidade, inerente ao próprio processo científico, e que qualquer mal que ela causasse seria consequência de sua má utilização por outros. (FEITOSA; DIAS, 2015, p. 53-54).

Entender a necessidade de pensar na formação docente é o que me leva a apontar a importância das teorias de currículo como agentes centrais nas discussões sobre o tornar-se professor. Através da análise do currículo como narrativa étnica e racial conseguimos deixar mais nítida a relação e importância da vinculação desses assuntos com a formação docente.

É através do vínculo entre conhecimento, identidade e poder que os temas de raça e de etnia ganham seu lugar na teoria curricular. O texto curricular, entendido aqui de forma ampla - o livro didático e paradidático, as lições orais, as orientações curriculares oficiais, os rituais escolares, as datas festivas - está recheado de narrativas nacionais, étnicas e raciais. Em geral, as narrativas celebram os mitos de origem nacional, confirmam o privilégio das identidades dominadas como exóticas ou folclóricas. Em termos de representação racial, o texto curricular conserva, de forma evidente, as marcas da herança colonial. O currículo é, sem dúvida, entre outras coisas, um texto racial. A questão da raça e da etnia não é simplesmente um "tema transversal": ela é uma questão central de conhecimento, poder e identidade. O conhecimento sobre raça e etnia incorporado no currículo não pode ser separado daquilo que as crianças e os jovens se tornarão como seres sociais (SILVA, 2015, p. 101).

Vejo a utilização das experiências individuais como parte fundamental para a vinculação das questões raciais e o ensino de ciências e biologia, isso porque a realidade não pode estar deslocada do que se constrói na universidade e o que se leciona nas escolas. Segundo Bell Hooks (2013):

$\mathrm{O}$ ato de ouvir coletivamente uns aos outros afirma o valor e a unicidade de cada voz. Esse exercício ressalta a experiência sem privilegiar as vozes dos alunos de 
um grupo qualquer. Ajuda a criar uma consciência comunitária da diversidade das nossas experiências e proporciona uma certa noção daquelas experiências que podem informar o modo como pensamos e o que dizemos. Visto que esse exercício transforma a sala de aula num espaço onde a experiência é valorizada, não negada nem considerada sem significado, os alunos parecem menos tendentes a fazer do relato da experiência um lugar onde competem pela voz, se é que de fato essa competição está acontecendo. Na nossa sala de aula, os alunos em geral não sentem a necessidade de competir, pois o conceito da voz privilegiada da autoridade é desconstruído pela nossa prática crítica coletiva (HOOKS, 2013, p. 114-115).

Bondía (2002) nos leva a refletir sobre a experiência individual como processo importante de transformação e de construção e reconstrução do saber.

Por isso, o saber da experiência é um saber particular, subjetivo, relativo, contingente, pessoal. Se a experiência não é o que acontece, mas o que nos acontece, duas pessoas, ainda que enfrentam o mesmo acontecimento, não fazem a mesma experiência. $\mathrm{O}$ acontecimento é comum, mas a experiência é para cada qual sua, singular e de alguma maneira impossível de ser repetida. O saber da experiência é um saber que não pode separar-se do indivíduo concreto em quem encarna. Não está, como o conhecimento científico, fora de nós, mas somente tem sentido no modo como configura uma personalidade, um caráter, uma sensibilidade ou, em definitivo, uma forma humana singular de estar no mundo, que é por sua vez uma ética (um modo de conduzir-se) e uma estética (um estilo). Por isso, também o saber da experiência não pode beneficiar-se de qualquer alforria, quer dizer, ninguém pode aprender da experiência de outro, a menos que essa experiência seja de algum modo revivida e tornada própria. (BONDÍA, 2002, p.27)

As experiências narradas ao longo da construção desta pesquisa, nos mostra também, a importância da narrativa como ferramenta da pesquisa qualitativa e, de sua relevância na análise dos diferentes aspectos das distintas realidades sociais.

A trajetória da pesquisa qualitativa confirma o fato de que tanto o relato da realidade produz a história como ele mesmo produz a realidade. As pessoas vão contando suas experiências, crenças e expectativas e, ao mesmo tempo, vão anunciando novas possibilidades, intenções e projetos. Às vezes, torna-se até difícil separar o vivido do que está por viver. Experiência e narrativa se imbricam e se tornam parte da expressão de vida de um sujeito. É por isso que se pode afirmar que a escrita sobre uma realidade pode afetar esta mesma realidade, pois assim como são os pensamentos que orientam a ação racional, a narração conduzirá ao desempenho de fatos vitais. (CUNHA, 1997, p.188)

Ver as diferenças como pilastra da construção de uma nova educação é enxergála através de uma perspectiva decolonial.

Então, se a colonialidade subalterniza e classifica o outro a partir das diferenças coloniais, retratando o poder da Europa frente às outras sociedades, a 


\title{
O
}

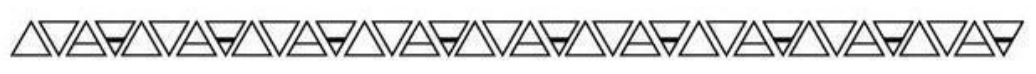

decolonialidade vem dar voz aos povos que, historicamente tiveram suas histórias, culturas e produções científicas e tecnológicas silenciadas sob efeitos da dominação colonial, promovendo a luta contra a marginalidade, a discriminação, a desigualdade e, a busca da transformação social através de um diálogo entre os povos que vivenciam a colonialidade. (CARDOSO; PINHEIRO, 2021)

Além disso, utilizo o conceito de Branquitude como lente teórica de análise desta pesquisa, afinal, falar sobre racismo é falar sobre os privilégios das pessoas brancas na sociedade e como essa construção é cultural e deve ser teorizada e exposta.

\begin{abstract}
A branquitude é um lugar de privilégios simbólicos, subjetivos, objetivo, isto é, materiais palpáveis que colaboram para construção social e reprodução do preconceito racial, discriminação racial "injusta" e racismo. Uma pesquisadora proeminente desse tema Ruth Frankenberg define: a branquitude como um lugar estrutural de onde o sujeito branco vê os outros, e a si mesmo, uma posição de poder, um lugar confortável do qual se pode atribuir ao outro aquilo que não se atribui a si mesmo (Frankenberg, 1999b, pp. 70-101, Piza, 2002, pp. 59-90). Neste ponto a autora argumenta que a identidade racial branca é o lugar da classificação social a partir da premissa de que a branquitude não seria uma identidade marcada. Quando se trata da idéia do significado da branquitude, prepondera o pensamento de que o branco não possui raça ou etnia. $\mathrm{O}$ branco não se encaixaria nos grupos, muitas vezes, denominados como minoria racial, étnica ou nacional (Cardoso, 2008, pp. 173-198). Em suma, a branquitude procura se resguardar numa pretensa idéia de invisibilidade, ao agir assim, ser branco é considerado como padrão normativo único. (CARDOSO, 2010, p.611)
\end{abstract}

E é por isso que reafirmo que a nossa formação de professor de ciências e biologia deve se comprometer para com a vinculação das questões raciais como parte fundamental do nosso processo formativo.

\section{PERCURSOS METODOLÓGICOS}

Para a realização dessa pesquisa foi elaborado um questionário virtual destinado a todos os professores formadores que ministram disciplinas ao curso de Ciências Biológicas da Universidade Federal do Ceará. A lista de docentes foi obtida a partir do Sistema Integrado de Gestão de Atividades Acadêmicas (SIGAA). O questionário teve o intuito de levantar informações que evidenciem o evento de silenciamento das questões étnicoraciais na formação dos futuros professores de ciências e biologia.

A utilização do questionário virtual foi escolhida tanto para evitar entrevistas presenciais, levando em consideração a pandemia do novo Coronavírus, ocasionando a 
COVID-19, como também com o objetivo de alcançar uma quantidade maior de docentes. Além de garantir o anonimato dos que irão responder, a forma como foi realizada preservaria a liberdade de resposta aos que se disponibilizaram a participar.

O questionário foi enviado a todos os docentes (exceto o orientador desse trabalho) que ofertam disciplinas para o curso de Ciências Biológicas da UFC no período de 2020.1 contando com disciplinas obrigatórias e optativas. A escolha de pesquisar os professores do curso surge a partir do reconhecimento da importância dessas pessoas para o processo de formação de outras pessoas e da urgência da centralização do debate étnico-racial nessa construção, expondo ainda mais a imprescindibilidade dos professores formadores nessas questões.

Além disso, existem marcos legais que garantem e centralizam esses debates no cotidiano escolar, como por exemplo: a Resolução CNE/CP n 2 , de $1^{\circ}$ de julho de 2015 Define as Diretrizes Curriculares Nacionais para a formação inicial em nível superior (cursos de licenciatura, cursos de formação pedagógica para graduados e cursos de segunda licenciatura) e para a formação continuada e a lei 10.639/03 que estabelece a obrigatoriedade do ensino da história e cultura afro-brasileiras e africanas nas escolas públicas e privadas do ensino fundamental e médio; o Parecer do CNE/CP 03/2004 que aprovou as Diretrizes Curriculares Nacionais para Educação das Relações Étnico-Raciais e para o Ensino de História e Cultura Afro-Brasileiras e Africanas.

No total o questionário foi enviado por e-mail para 76 docentes. Composto por 5 (cinco) questões é esperado com o questionário entender um pouco mais sobre como "anda" a relação desses docentes com as questões étnico-raciais e discutir sobre como isso impacta a formação dos futuros professores.

A produção do questionário surgiu a partir de elementos do Projeto Político Pedagógico do Curso (PPC) de Ciências Biológicas, o PPC pode ser encontrado na plataforma virtual da UFC, e de questionamentos que fui amadurecendo ao longo do meu percurso acadêmico. As perguntas que antes eram latentes no meu subconsciente e que poderiam ser vistas apenas como provocações de um militante apaixonado pela causa foram lapidadas em questionamentos científicos na perspectiva de obter das docentes respostas sucintas sobre a relação de suas aulas e as questões étnico-raciais. Adicionalmente, se existem alguma conexão entre suas disciplinas e essas questões e se estes docentes consideram suas aulas locais propícios para tratar sobre o tema. 
Minhas experiências foram o motivo principal para o surgimento e aprofundamento do questionamento levantado e baseando-me em Hooks (2013) e Bondía (2002) é que entendo minhas construções individuais como processo transformador, edificador e formador. Narrar as minhas experiências foi a forma metodológica que me debrucei inicialmente para desenvolver as problemáticas levantadas nesse trabalho. Trabalhar com narrativas na pesquisa e/ou no ensino é partir para a desconstrução/construção das próprias experiências tanto do professor/pesquisador como dos sujeitos da pesquisa e/ou do ensino (CUNHA, 1997).

A pesquisa qualitativa é crucial na construção metodológica e teórica deste trabalho, pois com ela consigo ver-me como professor pesquisador e enxergar-me dentro de uma produção científica crítica e coerente, onde o "eu" também é referência para a construção e reconstrução do conhecimento. O pesquisador é integrante do processo de conhecimento e interpreta os fenômenos, atribuindo-lhes um significado (BAPTISTA, 1994).

\section{O RETORNO DAS PERGUNTAS}

O Brasil nunca foi livre do racismo; pelo contrário, sua formação social tem marcas latentes da escravidão e do colonialismo europeu. Porém, atualmente o racismo que antes era velado hoje é explicitado e defendido como liberdade de expressão. Isso é visto nitidamente na televisão e na internet, onde discursos de ódio são compartilhados, agressões e mortes são comumente observadas e o corpo negro é cada vez mais banalizado e desumanizado.

Ao mesmo tempo que os tensionamentos das questões étnico-raciais estão mais explícitos mundialmente e os debates mais abrangentes, o conservadorismo e o racismo vem também disputando seu espaço na sociedade.

Inicialmente o questionário que foi a minha principal ferramenta metodológica foi enviada para 76 docentes como explicitado no tópico anterior. Porém, não tive uma quantidade expressiva de respostas no primeiro momento, tendo apenas três após sete dias do envio para o público respondente. $\mathrm{O}$ e-mail com o questionário foi reenviado pela segunda vez, e por volta de mais ou menos uma semana foi reenviado novamente. Ao final 
de mais ou menos 21 dias resolvi iniciar as análises das respostas com um total de 14 respondentes.

O questionário contava com 5 perguntas no total, onde a primeira servia como um controle, onde apenas era pedido para que fosse informada qual ou quais disciplinas eles ministravam para o curso. As outras seguintes eram destinadas a entender a (in)existência da relação de suas disciplinas e as questões raciais.

\section{RELEVANTE OU NÃO? A neutralidade no silenciamento ao questionário}

O que um estudante de Biologia tem a ver com questão racial? Talvez muitos dos docentes que viram meu e-mail e a apresentação do meu questionário devem ter se perguntado isso. A Biologia é encaixada como uma das Ciências da Natureza, segue a definição de Ciências da natureza presente nos Parâmetros Curriculares Nacionais (PCN's) do Brasil:

Nas diretrizes e parâmetros que organizam o ensino médio, a Biologia, a Física, a Química
e a Matemática integram uma mesma área do conhecimento. São ciências que têm em
comum a investigação da natureza e dos desenvolvimentos tecnológicos, compartilham
linguagens para a representação e sistematização do conhecimento de fenômenos ou
processos naturais e tecnológicos. As disciplinas dessa área compõem a cultura científica
e tecnológica que, como toda cultura humana, é resultado e instrumento da evolução
social e econômica, na atualidade e ao longo da história (BRASIL, p. 23).

Levando isso em consideração entendemos que aparentemente as questões étnico-raciais "não se encaixam" para ser debatido dentro do mesmo ambiente destinado a Ciências da Natureza gerando em muitos docentes sentimentos como o de irrelevância com essas questões se comparado ou relacionado a sua área de atuação. E foi isso um dos primeiros pontos observados com os resultados deste questionário: uma omissão massiva dos docentes.

O questionário enviado para os professores trazia questionamentos que os levavam a pensar e repensar suas disciplinas, o que pode ter gerado uma sensação de desconforto, além de, grande parte dos docentes a quem essa pesquisa foi encaminhada são professores que estão dentro da lógica do ensino e da pesquisa nas áreas das Ciências da Natureza (professores da Física, Química, Matemática, Estatística, e, óbvio, os da Biologia e suas diversas subáreas) o que pode explicar a omissão da maior parte deles para com a resposta do questionário, como um reflexo desse sentimento de irrelevância para com o debate étnico-racial.

Porém, esse sentimento de irrelevância pode ser explicado através de um processo político histórico de neutralização da Ciência. Essa neutralidade é percebida através de uma isenção 
científica para com diversos assuntos latentes na sociedade em que a Ciência é "livre de posicionamentos".

A neutralidade implícita na tese de que a ciência é ou não é neutra é evidentemente uma neutralidade em relação a valores; prova disso é que em muitos contextos, em lugar de "a ciência é neutra" se diz sinonimamente "a ciência é livre de valores". Os valores neste contexto são os valores sociais, definidos como aqueles que podem variar de cultura para cultura, de época para época, ao longo da história de cada cultura, e de grupo social para grupo social, nas sociedades marcadas por contradições internas. Já nesse nível de generalidade podem ser indicadas duas implicações fundamentais da tese. Ao isolar a ciência da esfera valorativa, a tese da neutralidade, primeiro, coloca a ciência fora do alcance de questionamentos em termos de valores sociais sendo essa a implicação mais relevante de um ponto de vista interno à cultura ocidental e, segundo, permite que a ciência seja posta como um valor universal o que é relevante especialmente no que se refere às relações da cultura ocidental com outras culturas (OLIVEIRA, 2008, p. 2).

Essa neutralidade científica é construída historicamente com pressupostos que contraditoriamente mostram o quão falso essa neutralidade é e que na verdade posiciona a Ciência nas mãos das classes dominantes. Antigamente, nas mãos dos grandes burgueses europeus que a utilizavam como suporte para a dominação de povos e, atualmente, nas mãos do capitalismo neoliberal que explora a mão de obra trabalhadora e fortalece as desigualdades sociais.

A desconstrução dessa visão neutra da Ciência é fundamental quando pensamos em avanços que o debate científico pode chegar, afinal, a Ciência já foi utilizada como pressuposto que dá base para o racismo.

Os efeitos econômicos da industrialização nascente agravaram as tensões sociais e colocavam em questão o próprio regime, cuja legitimidade a elite dirigente procurava justificar por todos os meios. Assim, para os intelectuais brasileiros, as crises sociais e econômica da época aconteciam sobretudo devido ao clima tropical e a constituição étnica do povo e não por questões históricas ou políticas. Esta argumentação, eles a foram buscar na "ciência" que chegou no país (final do século XIX), na adoção entusiástica do darwinismo social, do racismo "científico" e da eugenia, que como já foi visto, foram originalmente popularizados enquanto justificativas teóricas de práticas imperialistas de dominação. (BOLSANELLO, 1996, p. 158).

A necessidade de disputar esse espaço e mostrar que a Neutralidade na verdade tem um lado é importantíssimo, afinal, essa visão de Ciência neutra nos leva a não questionar que Ciência estamos produzindo, causando a omissão em assuntos que são de extrema relevância para o avanço social, como o da superação das desigualdades sociais.

Paralelo a isso, é crucial destacar que o ambiente acadêmico acaba por postergar essa visão de neutralidade. O que tem relação direta com o tipo de ciências que estamos ensinando na 
sala de aula, afinal, a nossa formação tem ligação explícita com que tipo de professores seremos. Questionar e repensar a formação docente é romper com um sistema de propagação de valores, que corrobora com práticas que fortalecem princípios antigos e conservadores que nos prende numa realidade muito distante da real nos afastando de uma prática docente engajada e livre de amarras estruturais como o racismo.

\section{ENTRE CONCEPÇÕES E RACISMO A BRANQUITUDE É EXPLÍCITA}

Prosseguindo com a análise do questionário, chegamos na segunda questão da pesquisa, que traz como indagação: O que os termos "étnico-raciais" lhe remete? Com essa pergunta era esperado entender um pouco sobre o que vêm aos docentes quando confrontados de forma aberta e direta sobre essas questões.

Entender o que se passa aos docentes sobre esses termos é também um exercício de observar como isso o atravessa e se reflete em sua prática docente.

Nesse tocante, temos que o papel do profissional de educação é fundamental, haja vista atuar cotidianamente na formação básica de toda uma população que engendra as muitas maneiras de agir em sociedade, que resvalam em processos de inclusão e exclusão nas variadas instâncias sociais que vão desde o ambiente psicossocial ao do trabalho e do acesso aos bens produzidos. (LIMA; SOUZA; NASCIMENTO, 2016, p. 20).

A maior parcela dos professores teve similaridades em suas respostas, trazendo as questões identitárias como principal forma de explicar os termos. Cito as principais palavras e expressões que foram utilizados: grupo de pessoas identificadas por cor; cor de pele; cultura; raça; origem étnica; ligação sentimental/afetiva/política; origem; história; população negra brasileira; população indigena.

Os processos de identificação são cruciais quando falamos sobre o debate étnico-racial, afinal, a sociedade brasileira historicamente nos constrói com um falso discurso de igualdade baseado nos discursos de mestiçagem. Porém, sabe-se quão problemático é falar sobre mestiçagem, afinal a identidade negra e também indigena foram diluídas como uma estratégia para o branqueamento social e como um reforço da supremacia do homem branco.

No Brasil e nas Américas, a mestiçagem foi um fenômeno e um fato emblemático. Ela é o resultado, o ato generalizado da violência, do defloramento forçado das mulheres escravizadas e de práticas amplamente recorrentes de iniciação dos filhos brancos da casa grande com as mulheres escravizadas, já largamente analisadas pela historiografia (Bomfim, 1993; Chiavenato, 1987; Gorender, 1991, 1992; Moura, 1989, 1990; Freyre, 
2009). Essa prática repetida em todo o período colonial evidencia a materialidade real e social da violência instaurada e introjetada pelo sistema patriarcal e escravocrata na sociedade brasileira. É o corpo, principalmente da escravizada, que passa a ser objeto do desejo erótico de um longo "processo de sucção sexual e social" (Sant'Anna, 1985, p. 25) em que predomina a "mais-valia do sexo e do dinheiro" (Ibid., p. 33), em que o "feitor e o senhor de engenho rondam as escravas como sanguessugas e vampiros, exercitando, econômica e eroticamente, sua oralidade perversa" (Ibid., pp. 25-26). É a partir desse ato de caráter econômico, sexual e racial que a mestiçagem será o principal elemento da teorização das raças no Brasil. (CONCEIÇÃO, 2020, p.32)

Reconhecer a importância da identidade e da representação e explicitá-la através de uma associação livre quando questionado sobre as questões étnico-raciais, demonstram como os docentes a entendem e enxergam a pluralidade na construção da população brasileira. Isso é fundamental quando pensamos a diversidade de corpos que esses docentes encontram ao longo dos anos de sua docência, explicitando ainda mais a urgência em centralizar e aprofundar essas questões para além do achismo, mas em uma construção crítica para com a análise e entendimento do Brasil. Assim, gerando um reflexo na sala de aula, onde as vozes serão ouvidas os corpos reconhecidos e as construções individuais respeitadas.

Paralelo a isso alguns professores destacaram outros pontos que devem ser citados e destacados que também orbitam e dão significado aos termos étnico raciais, sendo eles: racismo; exclusão; direitos.

Falar sobre raça é diretamente falar sobre racismo, afinal, a história das raças é a história da constituição política e econômica das sociedades contemporâneas (ALMEIDA, 2018), e a sociedade contemporânea é marcada pelo capitalismo, que é fruto das políticas colonialistas europeias.

A expansão europeia do século XVI tem o colonialismo como seu componente central e são as relações de produção e acumulação primitiva e demais processos históricos engendrados nesse contexto que tornaram o capitalismo possível como "modo de produção". Por outro lado, o capitalismo estendeu as relações coloniais sobre o espaço e as formas sociais, atualizando-o como componente estrutural de seu próprio sistema e amplificando de forma nunca antes vista sua dimensão e significado, tornando-o onipresente na história das diferentes sociedades. (FERREIRA, 2014, p. 255)

É quase inevitável não pensar em racismo quando estamos falando sobre esse tema e por isso que alguns docentes trouxeram a exclusão e a falta e busca de direitos como o ponto central quando questionados sobre, afinal, o racismo enquanto processo político e histórico é também um processo de constituição de subjetividade, de indivíduos cuja consciência e os afetos estão de algum modo conectados com as práticas sociais. (ALMEIDA, 2018 p,49) 
Todas as concepções dos professores formadores sobre a questão proposta são relevantes para entendermos o evento de silenciamento, inclusive os que expressaram de forma explícita os seus pontos de vista. Sobre, entre eles temos a seguintes afirmações que valem ser destacadas:

"Não vejo nenhuma diferença";

"Não remete a coisa alguma”;

“a nada, não tenho nada contra qualquer ser humano”.

Uma das respostas veio de um docente que não identificou a disciplina que ministra e as outras são de professores das Ciências da Saúde. Essas respostas explicitam e validam pra mim o sentimento de desconforto que sentia diversas vezes estando no campus (espaço físico) dessas áreas, um local elitizado e de presença quase unânime de pessoas brancas. Entendo essas afirmações como a expressão nítida da não importância para com assuntos relacionados com as questões raciais e o sentimento de irrelevância para com eles. "Nada me remete", "não vejo nenhuma diferença", "não tenho nada contra qualquer ser humano" são frases que ao mesmo tempo que demonstram na prática a visão de neutralidade científica comprovam quão irrelevantes estes assuntos são vistos por docentes que atuam diretamente na construção de futuros profissionais, não só da área da educação, mas futuros médicos, enfermeiros, farmacêuticos, entre outros que têm contato com docentes que desvalorizam a importância de questões que quebram com a lógica do racismo e assim contribuindo com a sua perpetuação.

A lógica da Branquitude embasa essas discussões quando pensamos na importância das pessoas brancas para a superação do racismo. É importante entender a branquitude como uma ideia de que o sujeito branco não tem raça ou etnia e que corresponde ao padrão normativo único, o "natural" (MARIN, NUNES, CASSIANI, 2020). Conceição (2020) nos mostra as diferenças dentro do conceito de branquitude e nos embasa nessa discussão.

[...] daí decorrendo sua hipótese de que há uma branquitude crítica e outra branquitude acrítica. Inicialmente, a branquitude crítica seria o "indivíduo ou grupo branco que desaprova publicamente o racismo" (Ibid., p. 178), e a branquitude acrítica o fenômeno "individual ou coletivo que sustenta o argumento em prol da superioridade racial branca" (Cardoso, 2009, p. 3). Consequentemente, sua posição é não naturalizar o racismo e a branquitude em que a identidade racial branca seria impreterivelmente racista, logo, a "única alternativa encontrada seria a extinção da branquitude" (Cardoso, 2008, p. 176). A afirmação de Lourenço Cardoso de que "o problema não está na diferença, e sim na utilização da distinção que objetiva a inferiorizar" (Santos, 2006d, p. 290 apud Cardoso, 2008 , p. 176) se coaduna com o que afirmei no primeiro capítulo deste ensaio, a relação entre diferença e desigualdade. (CONCEIÇÃO, 2020 p.64)

A superação do racismo só é possível a partir de uma construção coletiva, onde todas as pessoas são responsáveis por esse processo, inclusive as pessoas brancas. 
Entretanto, um dos elementos centrais da branquitude seria o privilégio, componente que envolve todos os brancos, críticos ou não, em algum grau, já que ser relacionalmente mais claro impõe de forma indelével uma posição de vantagem que independe muitas vezes do sujeito. Tal posição não se vincula a sentidos objetivos, mas sim a uma série de práticas sociais sutis que a brancura garantiu ao longo dos séculos e que independem simplesmente de nosso desejo de nos posicionarmos criticamente ou não. (CONCEIÇÃO, 2020 p.65)

Problematizar discursos que isentam e individualizam essas questões, como as expressas pelas respostas dos professores, nos ajuda a identificar o racismo presente e explicitar a branquitude dessas pessoas e como ela tem impacto direto na sociedade.

\section{PURA BOBAGEM?}

Metodologicamente o questionário foi pensado seguindo a lógica para com as respostas. Onde, após entendermos de "onde vêm" (no sentido de suas áreas de estudo) os docentes e o que traziam sobre o assunto, o questionário os levavam a pensar na relevância desse assunto na formação dos futuros professores e se existe alguma relação das questões étnico-raciais na(s) disciplina(s) por ele ministrada(s).

A questão três trazia como questionamento:

"Como o entendimento sobre a temática da questão anterior pode(m) contribuir para a formação dos(as) biólogos(as) professores de Ciências e Biologia?”

E a questão quatro:

"Como a inter-relação entre: disciplina(s) ministrada(s) por você e questões étnico raciais colaborariam na atuação dos(as) futuros(as) Biólogos professores em sala de aula no ensino básico?”

As duas questões serão analisá-las conjuntamente levando em consideração que as perguntas se completam e consequentemente suas respostas também.

Para uma melhor sistematização e compreensão das respostas, os professores foram separados em 3 grupos de acordo com as similaridades das respostas. E para facilitar a comparação das respostas, foram utilizadas as seguintes denominações, $R$ (respondente) e números (ex: R1) para melhor identificá-los, como também, preservando seu anonimato. O primeiro grupo são professores que responderam a questão três do questionário por meio de uma perspectiva de cidadania. Foram respostas deste grupo:

R1: "A partir do reconhecimento de raça e a valorização como inserção de mais pessoas de que fazem parte das minorias, sejam inseridas na formação. ”; 
R2: "O professor de qualquer área de conhecimento deve ser partícipe da luta pela superação do racismo na sociedade brasileira.";

R3: "Amenizando o preconceito, como também favorecendo a tolerância e a convivência. Pois, somos todos iguais.";

R4: "Com palestras/cursos de formação para os esclarecimentos sobre o tema preconceito vs étnico-racial";

R5: "Os docentes têm que ter o entendimento das diferenças sociais para melhor lidar com seus alunos";

R6: "É a formação e exercício da cidadania independente de disciplina e de profissão.";

R7: "Formação de ser que respeita à etnia, a raça e a diversidade";

R8: "Ampliar acesso ao conhecimento".

Nota-se que através destas falas, os aspectos que associam a importância do tema para com o melhor convívio social e da superação do racismo como uma importante ferramenta para uma sociedade mais justa. É nítido o reconhecimento destes professores para com a relevância desse tema na formação dos profissionais Biólogos(as) professores. Percebe-se que as noções de cidadania são ressaltadas pelos professores quando demonstram que as questões raciais devem ser parte presente da formação.

Relativamente ao ensino de Ciências, Krasilchik (1987), Melo (2000) e Santos (2006) mostram que, nos anos 1950-1960, se enfatizava o método científico, priorizando, para a aprendizagem de conteúdos conceituais, a participação de estudantes em atividades de laboratório. Nos anos 1970, esses autores indicam o surgimento do movimento "ciência, tecnologia e sociedade" (CTS) e a valorização da relação entre conhecimento científico, desenvolvimento tecnológico e vida social. Apontam também que, em consequência do movimento CTS e de outros fatores sociais, nos anos 1980 se inicia uma forte influência de referências construtivistas nas práticas pedagógicas e na pesquisa sobre tais práticas, que se verifica na contemporaneidade. Prosseguindo, os mencionados autores assinalam, nos anos 1990, a centralidade da discussão sobre as interações entre ensino de Ciências e formação para a cidadania, entendidas como reflexo do contexto sociopolítico da sociedade brasileira. No contexto atual, cerca de vinte anos após o fim de uma ditadura militar, as práticas democráticas se consolidam e a noção de cidadania perpassa políticas públicas de educação e discursos sobre a sociedade. Coerentemente com tal contexto, a noção de cidadania perpassa também o ensino de Ciências e a produção de conhecimentos sobre este campo. (VERRANGIA, PETRONILHA, 2010 p. 707-708) 
Ao analisar as respostas deste mesmo grupo para a $4^{\circ}$ questão alguns pontos interessantes a serem analisados. As respostas estão dispostas seguindo a mesma ordem dos docentes da questão anterior. As respostas são:

R1: "A partir da representatividade e discussões por meio das disciplinas que abordem o tema de raça";

R2: "Minhas aulas são bastante interativas e, muitas vezes, trazemos para discussões assuntos fora do conteúdo da disciplina. É comum, os temas de racismo e homossexualidade serem trazidos pra sala de aula, afinal somos também educadores e não apenas professores.";

R3: "Na medida em que mostra a legislação em vigor...”;

R4: "Talvez com o uso das ferramentas estatísticas e exemplos no tema, levantando discussões sobre o mesmo”;

R5: "Na compreensão e aprendizado de lidar com o assunto de forma inclusiva”;

R6: "Em todas as disciplinas podemos pensar no desenvolvimento de projetos para se trabalhar às questões e relações étnicos-raciais. É possível pensar em projetos didáticos relacionados ao tema, por exemplo, valorização da cultura a partir de estudos da etnobotânica, projetos relacionados à diversidade étnico-racial, trabalhar a legislação, discutir as relações raciais, promover o respeito às várias etnias, dentre outros. ”;

R7: "Demonstrando as variações que há entre raças”;

R8: “Acho que apenas a Flora, pois abrange estudos etnográficos-botânicos mostrando a cultura botânica destes povos, sejam eles originários do continente ou os que vieram como escravos".

A primeira coisa que me chamou atenção nas respostas deste grupo foi como eles deram importância para essas questões, como alguns fizeram um exercício de repensar sua(s) disciplina(s) e identificar nelas locais onde as questões raciais se conectam e, também, podem ser trabalhadas de forma conjunta, mostrando como é possível sim a conexão das questões e das diversas áreas de atuação e reafirmando a sua importância na formação.

Dentro deste mesmo grupo, existem docentes que também expressam uma relação de importância, porém, a conexão entre sua(s) disciplina(s) e as questões não são nítidas, a aproximação destes só é possível através de projetos ou até mesmo na criação de disciplinas a parte que tratem do tema. No geral, com esse grupo é possível observar que mesmo dando 
importância e relevância às questões os docentes, não utilizam-se das construções que o debate racial pode gerar para a construção efetiva de suas disciplinas.

O segundo grupo é um conjunto de professores que mesmo com respostas semelhantes ao primeiro trouxeram elementos que os fizeram ser reagrupados. Esses professores trazem uma perspectiva biológica para a resposta da $3^{\circ}$ questão. O que é importante destacar, são elas:

R9: "Percebendo que disciplinas como genética, anatomia e fisiologia humana nos mostram que somos todos iguais. O fenótipo é influência também do meio, inclusive das relações sociais do indivíduo.";

R10: "Reforço de conceitos com base biológica e abordagem coerente para a quebra de preconceitos de inferioridade ou superioridade baseados em características fenotípicas. ”;

R11: "Proporcionar uma visão mais ampla dos aspectos biológicos interagindo com os históricos. Algo que éfundamental para educar."

As respostas destes professores expressam de forma significante uma perspectiva que traz uma relação direta da Biologia e de alguns de seus conceitos relacionados com as questões étnico-raciais exteriorizando ainda mais a importância dessa relação na construção dos futuros profissionais desta área.

A construção de um diálogo entre as questões biológicas e questões raciais é crucial na formação dos futuros professores de ciências e biologia, que dentro da sala de aula se deparam com contradições que fogem da sua zona de conforto e é na sua formação que essas relações devem ser fortemente discutidas e problematizadas, refletindo assim, na futura sala de aula em que esses professores se encontrarem.

Compreendemos que raça e racismo em termos biológicos devem ser adequadamente abordados, isto é, problematizados e discutidos. Caso contrário, incorremos no risco de continuar observando a disseminação de ideias ou discursos teoricamente superados com a mesma força que tinham em suas origens. Nesta perspectiva, consideramos que os livros didáticos não devem trazer teorias evolutivas como a de Charles Darwin sem problematizá-las socialmente na história, ou demonstrar modelos mendelianos preocupados com o acerto de cálculos matemáticos sem criticar as implicações que tais modelos trouxeram/trazem ao ideário do determinismo genético. (VIEIRA, 2015, p. 28) 
Quando chegamos na $4^{\circ}$ questão deste grupo, nos deparamos com algumas respostas que se ligam com as respostas da questão anterior e que nos leva a refletir ainda mais sobre as contradições de nossa formação. As respostas são:

R9: "Reforço a resposta anterior, fazendo uma proposição de aulas integradas no ensino básico: Biologia e História. Ou ainda em atividades complementares como numa feira de profissões, com a participação de profissionais negros e brancos.”;

R10: "No conteúdo abordado nas disciplinas não teria contribuição";

R11: "Acredito que a partir de uma reflexão sobre a vivência dos estudantes, de si mesmo enquanto futuro professor, relacionado aos currículos e teorias Curriculares mais recentes."

Semelhante às respostas do segundo grupo para com a $4^{\circ}$ questão, esses professores demonstram em seus discursos, alternativas que podem ser integradas na sua prática docente e que contribuíram nessa vinculação de áreas e conteúdo. Porém, ao mesmo tempo em que apontam a importância para com as questões raciais não identificam na sua(s) disciplina(s) um lugar apropriado para essas discussões enfatizando ainda mais a inexistência e o silenciamento desse debate na formação.

O último grupo, são professores que respondem tanto a $3^{\circ}$ como a $4^{\circ}$ questão com discursos problemáticos e racistas. $\mathrm{Na} 3^{\circ}$ questão são respostas destes professores:

R12 e R13: "Não vejo necessidade";

R14: "Em nada, pura bobagem".

Vale ainda ressaltar que dois professores responderam com "não vejo necessidade”.

Essas respostas nos mostram na prática como a nossa formação não é livre de pessoas racistas e que elas são reflexo da sociedade em que estamos inseridos. Deixando ainda mais latente a necessidade das questões étnico-raciais na construção dos futuros profissionais de nossa sociedade, sendo um instrumento de enfrentamento direto à propagação do racismo.

Se examinarmos criticamente o papel tradicional da universidade na busca da verdade e na partilha de conhecimento e informação, ficará claro, infelizmente, que as parcialidades que sustentam e mantêm a supremacia branca, o imperialismo, o sexismo e o racismo distorcem a educação a tal ponto que ela deixa de ser uma prática da liberdade. (HOOKS, 2013, p.45)

$\mathrm{Na} 4^{\circ}$ questão são também respostas destes professores:

R12: "Não vejo nenhuma maneira, anatomia é anatomia para todos"; 


\section{R13: "Nenhuma”;}

R14: "O biólogo é profissional como qualquer outro, e deve respeitar seu público. Não interessa a cor".

Ao explicitar na $3^{\circ}$ questão que não vêem nenhuma importância nas questões raciais na formação dos profissionais Biólogos e professores, seguindo a mesma lógica que será discutida na $4^{\circ}$ questão, como a prática individual desses docentes na sua(s) disciplina(s) onde não fazem nenhuma relação desses assuntos.

A análise rasa de igualdade trazida por esses professores que se quer analisa de uma forma mais crítica a sociedade que está a sua volta. Hook (2013) nos diz que o silêncio é um ato de cumplicidade, que ajuda a perpetuar a ideia de que podemos nos engajar na libertação negra revolucionária e na luta feminista sem a teoria.

É nítido também o não olhar crítico desses docentes para com a sala de aula em que eles se encontram, afinal, as cotas raciais reconfiguraram e democratizaram as vagas nas universidades públicas, então teoricamente na sala de aula desses professores existem pessoas negras periféricas, deficientes físicos, jovens que fogem do antigo padrão de alunos universitários e pluralizam e dão cor para a nova sala de aula.

São respostas como essas que, apesar de esperadas, de uma forma mais velada, ainda chocam quando trazidas de forma tão explícita e chocante. Porém, é inegável a contribuição destes professores para a construção deste trabalho, afinal, ao expressarem suas visões de forma gritante, o processo de silenciamento apontado anteriormente no questionamento do trabalho para com as questões étnico-raciais na formação.

Para nós que estávamos à margem (pessoas de cor, gente da classe trabalhadora, gays, lésbicas e por aí fora) e sempre tivéramos sentimentos ambivalentes sobre nossa presença numa instituição onde o conhecimento era partilhado de modo a reforçar o colonialismo e a dominação, era emocionante pensar que a visão de justiça e democracia que estava no próprio âmago do movimento pelos direitos civis iria se realizar na academia. (HOOKS, 2013, p.45)

\section{ESTAVA AQUI E VOCÊ NÃO VIU}

A $5^{\circ}$ questão deste trabalho, através de elementos do PCC das Ciências Biológicas, mostra que o reconhecimento de formas de discriminação racial assegurados através de pressupostos biológicos, devem ser uma competência e habilidade geral dos profissionais 
Biólogos(as) professores e que estas questões deveriam sim estar diretamente ligadas a formação desses futuros profissionais.

Segue a transcrição dessa questão: No Projeto Político Pedagógico do curso de Ciências Biológicas da UFC em seus Princípios Norteadores: ...Competências e habilidades gerais do biólogo (Parecer CNE/CES 1.301/2001) ... "b) Reconhecer formas de discriminação racial, social, de gênero, etc. que se fundem inclusive em alegados pressupostos biológicos, posicionando-se diante delas de forma crítica, com respaldo em pressupostos epistemológicos coerentes e na bibliografia de referência." Esse Parecer presente no Projeto Político Pedagógico do curso de Ciências Biológicas foi utilizado para a confecção da ementa da sua(s) disciplina(s)? Se não foi, como poderia ser inserido na disciplina que você ministra?

Foram agrupados conforme o tópico anterior os professores através das similaridades das respostas mantendo as mesmas identificações do tópico anterior. $\mathrm{O}$ primeiro grupo, são de cinco professores que ao serem questionados sobre a presença dessas questões na construção de suas ementas, ou caso não tivesse, como eles poderiam inserir esses debates na sua(s) disciplina(s) mostrarando em suas respostas entendimento acerca dessa interrelação, afirmando a sua importância e urgência.

São as respostas destes professores:

R1: "Não leciono disciplina no curso, porém, seria um tema abordado nos diversos temas que remetem ao cunho social.";

R3: "Na minha disciplina já é inserida na legislação...trago a discussão."

R6: “Acredito que tenha sido, pois o Projeto Pedagógico do curso foi pensado e formulado levando em conta as competências e habilidades gerais do biólogo (Parecer CNE/CES 1.301/2001) e as ementas vigentes devem ter sido elaboradas considerando as mesmas.";

R9: "A emenda atual não contempla, mas percebo que pode ser inserida utilizando dados de saúde pública como exemplos deste contexto.”;

R11: "quando cheguei no curso, a ementa já estava feita. Contudo, nas práticas da disciplina, o que é mais importante, sempre tentei usar as relações humanas em sua diversidade como base para a práxis pedagógica.";

As respostas destes professores demonstram como a relação das questões étnicoraciais podem se apresentar na construção de metodologias, que podem transformar a sala 
de aula em um espaço que discute o social sem perder a "essência" de suas disciplinas. Hooks (2020) nos diz que quando enxergamos a sala de aula como um lugar onde professor e estudante podem compartilhar sua "luz interna", temos o caminho para vislumbrar quem somos e como podemos aprender juntos.

Podemos nos embasar para uma discussão mais aprofundada dessas questões através das análises curriculares. Entendendo essas análises através de uma perspectiva pós-estruturalista da teoria curricular, onde podemos dizer que o currículo é também uma questão de poder e que as teorias de currículo, na medida em que buscam dizer o que o currículo deve ser, não podem deixar de estar envolvidas em questão de poder (SILVA, 2015).

Entender as construções curriculares através dessa perspectiva é compreender que não existe neutralidade nas escolhas para essa construção, mas o exercício do poder que a classe dominante exerce. Como vivemos em uma sociedade marcada por desigualdades sociais, as escolhas do que constrói ou não o nosso conhecimento é mais um elemento onde o poder dos grandes é obedecido.

Selecionar é uma operação de poder. Privilegiar um tipo de conhecimento é uma operação de poder. Destacar entre as múltiplas possibilidades, uma identidade ou subjetividade como sendo a ideal é uma operação de poder. As teorias do currículo não estão, nesse sentido, situadas num campo "puramente" epistemológico, de competição entre "puras" teorias. As teorias de currículo estão ativamente envolvidas na atividade de garantir o consenso, de obter hegemonia. As teorias do currículo estão situadas num campo epistemológico social. As teorias de currículo estão no centro de um território contestado. (SILVA, 2015, p.16)

O segundo grupo de professores são marcados pelo "não", ou não sabe, ou não participaram, ou não aplicam. São as respostas destes docentes:

R2: "Não se aplica à ementa da disciplina que leciono. ”;

R4: "Não sei informar";

R5: "Não sei”.

R7: "Não participei da construção do Ppc";

R8: “Não”;

R10: "Não foi porque as disciplinas não são do curso de biologia. Não foram utilizados na ementa das disciplinas";

Essas respostas nos mostram certa negligência ou mesmo desconhecimento de um documento norteador de uma formação profissional, para com essas questões em suas 
disciplinas, levando em consideração que nas respostas das questões anteriores destacaram a importância das discussões étnico-raciais, mas que infelizmente não aplicam na prática docente devido a ideia de que essas questões não têm relações com sua(s) disciplina(s). Outra perspectiva importante, se baseia na inter-relação ou não dessas questões é através da análise do currículo por uma perspectiva multicultural. E a ausência de uma discussão dessa natureza por parte do corpo docente, envolvendo também os discentes, pode comprometer um processo formativo do currículo prescrito para um currículo oculto

Uma perspectiva crítica de currículo buscaria lidar com a questão da diferença como uma questão histórica e política. Não se trata simplesmente de celebrar a diferença e a diversidade, mas de questioná-las. Quais são os mecanismos de construção das identidades nacionais, raciais, étnicas? Como a construção da identidade e da diferença está vinculada às relações de poder? Como a identidade dominante tornou-se a referência invisível através da qual se constroem as outras identidades como subordinadas? Quais são os mecanismos institucionais responsáveis pela manutenção da posição de subordinada de certos grupos étnicos e raciais? Um currículo centrado em torno desse tipo de questões evitaria reduzir o multiculturalismo a uma questão de informação. Um currículo multiculturalista desse tipo deixa de ser folclórico para se tornar profundamente político. (SILVA, 2015 p. 102)

O último grupo, trata-se dos professores que não reconhecem a importância da vinculação destas questões na construção curricular de uma nova perspectiva de ensino baseada no antirracismo, são as respostas deles:

R12: "Acho uma tolice extrema”;

R13: "Acho uma grande bobagem”;

R14: "Acho que estão totalmente equivocados".

As expressões usadas por esses professores para responderem essas questões são exemplos nítidos, do incômodo que debater sobre racismo e formular sobre a construção de uma educação que centraliza também esses tensionamentos e dão base para uma nova perspectiva educacional, podem causar. Essas pessoas estão imersas em uma lógica que as favorece e reconhecer isso é um movimento nada interessante, afinal, o conforto e a seguridade que elas têm, a partir do seu lugar de autoridade docente, impedem de olhar de uma forma mais crítica e até sensível a sua sociedade e principalmente o seu papel dentro dela, afinal, são docentes que estão na construção efetiva de futuros profissionais.

\section{O FIM OU O INÍCIO?}


A construção deste trabalho para além de suas obrigações acadêmicas foi um momento de reconstrução da minha intelectualidade e um exercício para minha autoestima. A academia por ser um ambiente em que a competição é estimulada, um reflexo do sistema capitalista, nos leva a duvidar de nós mesmos e da nossa capacidade. Diversas vezes em minha formação me vi nesse local e sentia o não pertencimento, porém, como trago, ao longo da minha escrita, a coletividade e os movimentos sociais me mostraram que aquele era meu local também e me deram forças para continuar e principalmente a lutar para que esse local se torne um ambiente confortável para todos aqueles que se parecem comigo.

A responsabilidade para com o enfrentamento desse evento é de todos, que se propõem a contribuir na construção de uma nova formação docente, cidadã e na constituição de uma educação antirracista. Alguns respondentes do questionário nos mostraram alternativas que nos levam a evidenciar como é possível a vinculação de áreas que são colocadas como opostas, mas que na verdade podem sim ser construídas conjuntamente. A transversalização de conteúdos, a valorização das individualidades e a recuperação histórica das ancestralidades são exemplos práticos de vinculações possíveis.

A educação antirracista é um projeto de nação; sua construção se dá a partir de ferramentas que como essa escancaram o envergamento da educação para com os valores do capitalismo. É através da exposição de questões antes ocultas e silenciadas que podemos finalmente nos debruçar nas soluções destes problemas.

Como futuro professor de ciências e biologia vejo a minha prática docente como um local de reconstrução e de valorização das identidades. Não é utilizando as questões étnico raciais como um extra nas disciplinas ou as tornando exóticas que conseguiremos avançar para a superação do racismo, mas sim, enxergando essas formulações como noções centrais para uma construção descolonizada e intercultural.

Muito temos que avançar. Hoje a universidade começa a ser Brasil e é essa diversidade de cores, pessoas e culturas que ocupando esse espaço, de construção de profissionais cidadãos, pode encabeçar o movimento de transformação. Uma transformação onde todas as vozes são ouvidas e o único silenciado será aquele que tenta nos calar.

\section{REFERÊNCIAS BIBLIOGRÁFICAS}

ALMEIDA, S. L. O que é racismo estrutural? 1. ed. Belo Horizonte: Letramento, 2018. v. 1. 204 p. 
BAPTISTA, D. M. T. O debate sobre o uso de técnicas qualitativas e quantitativas de pesquisa. O Uso de abordagens qualitativas em Serviço Social: Um desafio Instigante, São Paulo, v. 1, n.1, p. 19-26, 1994.

BRASIL. LEI $N^{o}$ 12.711, DE 29 DE AGOSTO DE 2012. Dispõe sobre o ingresso nas universidades federais e nas instituições federais de ensino técnico de nível médio e dá outras providências. Brasília, 2012. Disponível em:〈http://www.planalto.gov.br/ccivil 03/ ato2011-2014/2012/lei/l12711.htm >

BRASIL. Orientações Educacionais Complementares aos Parâmetros Curriculares Nacionais do Ensino Médio. PCN, Ensino Médio. Ciências da Natureza, Matemática e suas Tecnologias. Disponível em: < http://portal.mec.gov.br/seb/arquivos/pdf/CienciasNatureza.pdf >

CARDOSO, Lourenço. Branquitude acrítica e crítica: A supremacia racial e o branco antirracista. Revista Latinoamericana de Ciencias Sociales, Niñez y Juventud, v. 8, n. 1, p607-630, 2010.

CARDOSO, Silná Maria Batinga; PINHEIRO, Bárbara Carine Soares. INDÍCIOS DE UMA PERSPECTIVA (DE)COLONIAL NO DISCURSO DE PROFESSORES (AS) DE QUÍMICA SOBRE AS RELAÇÕES ÉTNICO-RACIAIS. Revista da Associação Brasileira de Pesquisadores/as Negros/as $(A B P N)$, [S.1.], v. 13, n. 35, p. 464-492, fev. 2021. ISSN 2177-2770. Disponível em: <https://abpnrevista.org.br/index.php/site/article/view/902>. Acesso em: 27 abr. 2021.

CONCEIÇÃO, Willian Luiz da. Branquitude Dilema racial brasileiro. Rio de Janeiro: Papéis Selvagens, 2020.

Disponível

em: <http://www.papeisselvagens.com/uploads/6/9/3/3/69339767/branquitude_dilema_racial_brasileiro.pdf $>$ Acesso em: 05 out. 2020.

CUNHA, Maria Isabel da. CONTA-ME AGORA! as narrativas como alternativas pedagógicas na pesquisa e no ensino. Rev. Fac. Educ. vol. 23 n. 1-2 São Paulo Jan./Dec. 1997.

FEITOSA, Raphael Alves; DIAS, Ana Maria Iorio. Um pouco de filosofia da ciência para compreender currículos. In: FEITOSA, Raphael Alves; DIAS, Ana Maria Iorio. Ensino, currículo(s) e formação docente: mandala(s) como expressão da omnilateralidade e das ciências. 1. ed. Jundiaí: Paco, 2015. v. 1, cap. 2, p. 53-105. ISBN 978-85-848-860-8

FERREIRA, Andrzey C. Colonialismo, capitalismo e segmentaridade: nacionalismo e internacionalismo na teoria e política anti e pós-colonial. Sociedade e Estado (UnB. Impresso), v. 29, p. 255-288, 2014

HOOKS, Bell. Ensinando a transgredir: a educação como prática da liberdade. São Paulo: Editora WMF Martins Fontes, 2013.

HOOKS, Bell. Ensinando pensamento crítico: sabedoria prática. São Paulo: Editora Elefante, 2020.

LIMA, Marinalva Vilar de; SOUZA, Antonio Clarindo Barbosa de; NASCIMENTO, Celso Gestermeier do. RELAÇÕES ÉTNICO-RACIAIS: formação de professores e responsabilidade da universidade brasileira. In: SOUZA, Antonio Clarindo Barbosa de; OLIVEIRA, Ariosvalber de Souza; LIMA, Marinalva Vilar de (org.). EDUCAÇÃO PARA AS RELAÇÕES ÉTNICO-RACIAIS: identidades, etnicidades \& alteridades. IDENTIDADES, ETNICIDADES \& ALTERIDADES. Campina Grande: Editora do Ccta/ufpb, 2016. p. 1-326. Disponível em: <http://www.ccta.ufpb.br/editoraccta/contents/titulos/historia/educacao-para-as-relacoes-etnicoraciais/etnicoraciais_identidadesetnicidadesealteridades.pdf>. Acesso em: 23 de junho de 2020.

OLIVEIRA, Marcos Barbosa de. Neutralidade da ciência, desencantamento do mundo e controle da natureza. São $\quad$ Paulo, $2008 . \quad$ Disponível em: <https://www.scielo.br/scielo.php?script=sci_arttext\&pid=S1678-31662008000100005 >. 
SILVA, Tomaz Tadeus da. Documento de identidade: uma introdução às teorias de currículo. 3. ed. Belo Horizonte: Autêntica, 2015. P. 154.

VERRANGIA, Douglas; Silva, Petronilha Beatriz Gonçalves. Cidadania, relações étnico-raciais e educação: desafios e potencialidades do ensino de ciências. Educação e Pesquisa (USP. Impresso), v. 36, p. 705-718, 2010.

VIEIRA, EDUARDO PAIVA DE PONTES; MARTINS, FRANCE FRAIHA. Aspectos históricos e epistemológicos relacionados ao conceito de raça humana e a formação de professores de ciências e Biologia. Amazônia - Revista de Educação em Ciências e Matemáticas (Online), v. 11, p. 22-33, 2015

Recebido em: 27/04/2021

Aprovado em: 18/10/2021 